\title{
On the Efficiency of Text Production in Vocabulary Learning: An Empirical Study on Iranian GFL-Learners
}

\author{
Nader Haghani ${ }^{1,2}$ \& Samira Kiani ${ }^{2}$ \\ 1 Research Institute ReCeLLT, University of Tehran, Tehran, Iran \\ 2 Faculty of Foreign Languages and Literatures, University of Tehran, Tehran, Iran \\ Correspondence: Nader Haghani, Research Institute ReCeLLT, University of Tehran, Tehran, Iran; Faculty of \\ Foreign Languages and Literatures, University of Tehran, Tehran, Iran. E-mail: nhaghani@ut.ac.ir
}

Received: February 10, $2018 \quad$ Accepted: March 5, $2018 \quad$ Online Published: March 20, 2018

doi:10.5539/jel.v7n3p176 URL: https://doi.org/10.5539/jel.v7n3p176

\begin{abstract}
The concept of text-oriented vocabulary exercises is based on Kühn's (2000) three-step model of vocabulary teaching - receptive, reflective and productive vocabulary exercises - which focuses on working with texts. Since the production is in principle more exhausting than the reception-as can be seen from the Levels of Processing Effect - one can assume that it comes to a deeper processing in the text production and consequently exerts a positive influence on the retention performance of the learners. The main purpose of this paper is to conduct an empirical study on Iranian GFL-learners (Note 1) to demonstrate whether text production has a positive impact on the short-term, medium-term and long-term retention of the GFL-learners who have learned the new words in foreign language based on the concept of text-oriented vocabulary exercises or not. In addition, this study also has the secondary object of demonstrating the possibility of GFL-Learner's sex as well as the age having any effect on the retention performance. The results have shown that the text production has a positive effect on the short-term and medium-term retention. It could also be shown that gender exerts an influence on the medium-term retention performance of female GFL-learners. In terms of age, the result was that text production has a positive impact on the retention performance of the 30 to 40 -year-old GFL-learners, enabling them to better remember the textually learned words in the short, medium and long term.
\end{abstract}

Keywords: GFL-teaching, retention, vocabulary exercises, text production

\section{Introduction}

\subsection{Introduce the Problem}

Peter Kühn developed the three-step model of vocabulary teaching in foreign language didactics in 2000 and published an article about this model in issue 155-156 of the journal "Germanic linguistics" (Note 2) with the name "Studies on German as a Foreign Language, Vocabulary Exercises in Discussion" (Note 3) and entitled "Kaleidoscope of Vocabulary Didactics and Methodology, Traditional Vocabulary: Critical Surveys and Perspectives" (Note 4). The three-step model of vocabulary teaching says that vocabulary exercises should be done in three steps: The first step is receptive vocabulary practice, which involves understanding and explaining words with different semantization techniques. The second step is the reflective vocabulary practice, which includes the notation, gathering, linking, and ordering of words and phrases, and the third step is the productive vocabulary practice, which involves the use of the vocabulary in appropriate texts and situations. Based on his model, Kühn addressed the text-oriented vocabulary exercises in an article in 2007 titled "Evaluation of receptive and productive vocabulary skills, pleading for textual and constructivist vocabulary tasks" (Note 5).

Vocabulary teaching is not a new topic in German language teaching. The three steps that make up the three-step model of Kühn (2000) are also not a new topic in themselves because they were and are still being addressed and examined from different perspectives. The receptive vocabulary practice-as far as the frist step is concerned-was investigated by scientists such as Löschmann (1993), Köster (1994), Müller (1994), Robra (2000) and Kühn (2006 and 2007). Löschmann (1993) discussed efficient vocabulary exercises in his book and compared old and new methods (integrative, communicative, intercultural, cognitive and creative) and treated teaching and learning strategies and semantization techniques. In 1994, Köster published a book on semantization processes in GFL-Teaching, in which he dealt with the analysis of meaning explanations in 
classrooms with advanced learners. In the same year, Müller (1994) addressed methods of conveying meaning in the 8th Distance Learning Unit of the Goethe-Institute. In 2000, Robra addressed the subject of "self-semantization" in his article in the 31st issue of the journal "French Today" and tried to pursue the question of how learners can find out the meanings of unknown vocabulary as independently as possible. In 2006, Kühn proposed in his book "Intercultural Semantics" (Note 6) semantization techniques that can convey culture-specific meanings of words. These techniques can also sensitize learners to intercultural issues. In 2007, Kühn published the article "Receptive and Productive Vocabulary Competence" (Note 7) with textual and constructivist vocabulary tasks.

The modeling of the mental lexicon and the networking of new words in vocabulary learning - as far as the second step is concerned-have been the focus of discussion since the beginning of the 1980s. The most important work in this field may be the book "Words in the Head, An Introduction to the Mental Lexicon" (Note 8) by Aitchison (1997), which addresses the mental lexicon and tries to pursue the questions: How words are learned, understood and produced, stored and found? Numerous scientific papers and articles have been published in this field. Scientists such as Klippel (1995), Pilzecker (1996), Quetz (1998), Wolff (2002), Neveling (2004), Kersten (2010) and Žavski-Bahč (2012) devoted themselves to the study of the mental lexicon and the networking of words in foreign language learning from different angles. In 1995, Klippel wrote an article entitled "Word Networks" (Note 9), in which he addressed networked learning. In 1996, Pilzecker discussed the relationship between cognition and vocabulary practice in his article of the same title and in 1998, Quetz authored an article entitled "The Systematic Construction of a Mental Lexicon" (Note 10). Wolff (2002) also dealt with the topic and wrote an article on the mental lexicon as the basis of language proficiency in the mother tongue and foreign languages. In 2004, Neveling dealt with this topic in her $\mathrm{PhD}$ thesis entitled "Word Learning with Word sets, an Examination of Word sets as a Learning Strategy and Research Method" (Note 11). In her $\mathrm{PhD}$ thesis, the knowledge about the mental lexicon, especially in the field of learner autonomy, was put into practice and Neveling proposed a learning strategy for vocabulary learning using word networks as a storage and retrieval strategy, which promoted the long-term retention of words. Neveling proved their success in an empirical study. In 2010, Kersten examined the mental lexicon from the perspective of multilingualism in his article entitled "The Mental Lexicon and Vocabulary in Elementary School" (Note 12) and showed the models of the mental lexicon for early foreign language teaching. In 2012, Žavski-Bahč addressed the processes of language processing at the lexical-semantic level in his article "Reflections on the Mental Lexicon in the GFL-Teaching" (Note 13).

The productive vocabulary practice - as far as the third step is concerned - has also been much studied and treated by scientists such as Honnef-Becker (2000) and Scherfer (2007). The article by Honnef-Becker is especially relevant to this study. In 2000, Honnef-Becker thematized productive vocabulary practice in his article "Vocabulary Work in the Writing Workshop: Pleading for a Textual Vocabulary Teaching" (Note 14). He described the writing workshop as an appropriate place for productive vocabulary practice. Learners formulate and revise texts in such workshops individually, with a partner or through group work. In 2007, Scherfer dealt with exercise typology for vocabulary learning in an article and also proposed exercises for productive vocabulary learning.

Although the three steps in the three-step model of Kühn are not a new topic, the model itself has not received much attention. It is still in its infancy and can be scrutinized from different perspectives. Therefore, the present study aims to deal with this concept. It should be noted that this concept follows three general principles. The first principle is that the success of the concept should be measured by the output of the learners, which is evaluated by their success in using the words in their communications in an appropriate way. The second principle is the functional orientation. The concept aims at promoting the writing and/or speaking competence. From this principle, the third principle can be derived, namely the need for a textual orientation. The examination of texts makes it possible to observe lexical means in authentic usage contexts; it also makes it possible to use them in the production of own texts in an authentic way (Steinhof, 2011; Hochstadt et al., 2013). As can be seen from these three principles, the output of the learners plays an important role. The Output Hypothesis of Swain (1985) is based on the assumption that understandable input for acquisition and learning can be an important prerequisite, but it cannot guarantee that language correctness will be achieved. Without the active use of language (output), this is not possible. Elbers (1997) argued in her L1-acquisition-related variant (Note 15) of the Output Hypothesis that production is in principle more exhausting than reception, and it comes to a deeper processing and consequently exerts a positive influence on the retention performance of the learners (ibid., cit. by Aguado Padilla, 2002). This is stated in Levels of Processing Effect by Craik \& Lockhart (1972), which suggests that retention is due to the type of processing, the deeper and more thorough the processing is, 
the deeper and more lasting is retention performance. This allows one to claim that the text-oriented vocabulary exercises, because of their production phase, can lead to a better retention. The retention performance is the ability of a person to keep the recorded information more or less permanently in the memory. Neurologists-like Niggemann (1977) - explain that the degree of retention is dependent on the type of presentation of the information. The reading performance alone plays a minor role in gaining the new information (10\%). Winning the new information through listening makes it twice as easy to remember the information (20\%). If you win the new information by looking, you can keep the information three times better in the memory $(30 \%)$. If the information is obtained by seeing and hearing simultaneously, the retention level of the information increases up to $50 \%$. Speaking and discussing increase the retention rates up to $70 \%$ and doing up to $90 \%$ (Pipers/ Dabrowski, 2011; Stangl, 2014). Therefore, the use of the new information in the form of oral or written text production should lead to at least more than $70 \%$ retention of new vocabulary in learners. When referring to the concept of text-oriented vocabulary exercises, this question arises that: Is the text production-the third step in the concept - the crucial phase, which enables the learners to keep the learned words longer in mind? The present study tries to answer this question.

\subsection{Research Questions and Hypotheses}

In order to give a clear answer to the main mentioned question, the main question is formulated in 6 sub-questions:

- Question I: Is the production of text in the concept of text-oriented vocabulary exercises the decisive phase, which leads to a better short-term retention performance of the learners?

- Hypothesis I: Based on the Output Hypothesis and the Depth of Processing Theory, it is assumed that this question will find its positive answer after the experiment has been carried out and that learners who have learned new words in a text-oriented manner can show a better short-term retention performance.

- Question II: Is the production of text in the concept of text-oriented vocabulary exercises the decisive phase that leads to a better medium-term retention performance of the learners?

- Hypothesis II: Based on the Output Hypothesis and the Levels of Processing Effect, it is assumed that this question will find its positive answer after the experiment has been carried out and that learners who have learned new words in a text-oriented manner will be able to demonstrate a better medium-term retention performance.

- Question III: Is the production of text in the concept of text-oriented vocabulary exercises the decisive phase leading to a better long-term (after 1 week) retention of the learners?

- Hypothesis III: Based on the Output Hypothesis and the Levels of Processing Effect, it is believed that this question will find its positive answer after the experiment and that learners who have learned new words in a text-oriented manner can show better long-term (after 1 week) retention performance.

- Question IV: Is the production of text in the concept of text-oriented vocabulary exercises the decisive phase, which leads to a better long-term (after 3 weeks) retention performance of the learners?

- Hypothesis IV: Based on the Output Hypothesis and the Levels of Processing Effect, it is believed that this question will find its positive answer after the experiment has been conducted and that learners who have learned new words in a text-oriented manner will be able to show better long-term (after 3 weeks) retention performance.

- Question V: Is there any correlation between the positive impact of text production in the concept of text-oriented vocabulary exercises on short-term, medium-term and long-term retention performance, and gender of learners?

- Hypothesis V: According to Halpern's (2000) views and studies, there is a clear female advantage in terms of linguistic cognition in tasks that "require the writing of texts, involve grammatical constructions and an accurate use of words etc." (cit. by Lautenbacher et al., 2007). In this regard, women can perform better. Based on their views, it is believed that there is a correlation between the positive impact of text production in the concept of text-oriented vocabulary exercises on short-term, medium-term and long-term retention and gender of learners, and an advantage for the female gender can be found.

- Question VI: Is there any correlation between the positive impact of text production in the concept of text-oriented vocabulary exercises on short-term, medium-term and long-term retention performance and the age of learners?

- Hypothesis VI: It is important to mention that the participants in this study are mainly divided in the age group between 20 and 30 years who are called young adults and in the age group between 30 and 45 years who are 
called mature adults who have different needs, according to Bočková (2002). The 20 to 30-year-old people have very good prerequisites for learning, education and studying that are means of achieving their life goals. Adults between the ages of 30 and 45 have clear goals. Their interest in learning is influenced by their functional and professional position (ibid., cit. by Ludinová, 2008). As adults learn a new language, especially analytically and by means of rules and their needs, it can be assumed that there is a connection between the positive impact of text production in the concept of text-oriented vocabulary exercises and short-term, medium-term and long-term retention and age of the learners. In addition, according to the different goals of learners in these groups, mature adults are expected to benefit more and have a better retention of the learned words.

\section{Methodology}

\subsection{Participants}

In this study, 53 German learners $(n=53)$ participated. They were randomized to two groups (experimental group (EC) and control group (CG)).

The experimental group consisted of 28 participants $(n=28)$ : 50\% women, 50\% men. Most participants $(75 \%)$ were in the age group of 20 to 30 years, $7 \%$ in the age group under 20 years, $14 \%$ in the age group of 30 to 40 years and $4 \%$ in the age group of 40 to 50 years. They were all learners of German language at the ÖKF (Note 16). Their language skills, according to the classification in this language institute and the guidelines of the CEFR (Note 17), corresponded to the level end A2, but relying on the classification of the language institute, their language skills were not assessed. All participants were Iranians, their native language was Farsi, and they all had learned English as their first foreign language at school. 14\% of participants had also learned another foreign language such as French, Swedish, Arabic or Indian.

The control group consisted of 25 participants ( $n=25)$ : $56 \%$ women, $44 \%$ men. Most participants $(60 \%)$ were in the age group of 20 to 30 years, $4 \%$ in the age group under 20 years, $32 \%$ in the age group of 30 to 40 years and $4 \%$ in the age group over 40 years. They were all-like the participants in the EC-GFL-learners at the ÖKF. Their language skills, according to the classification in this language institute and according to the guidelines of the CEFR, corresponded to the level end A2, but this has not been investigated considering the classification of the language institute as reliable. All participants in this group were Iranians, their native language was Farsi, and they all had learned English as their first foreign language at school. 8\% of participants also had learned another foreign language such as Arabic or Turkish.

\subsection{Study Design}

The empirical study is performed on two groups of Iranian participants (EC and $\mathrm{CG}$ ) using the following methodological approach:

- Selection of a suitable text: It is important to note that this study will be limited to written text and it is not about oral text. The text selected for this study is from textbook "DaF Kompakt". The difficulty of the text and exact equivalent of the desired level are not checked and the textbook was deemed reliable.

- Determination of the new words in the text: For the entire textbook there is a word list, where you can find out which words are learned in which lesson and belong to which level. With the help of this list and the program "Profile German" the new words in this text and their levels are determined.

- Choosing of participants and their demographic issues (age, sex, and foreign language): The participants are GFL-learners in the language institute ÖKF. They should answer ten demographic questions, so one can be sure that they are suitable for this experiment. A number of twenty-five participants in each group are ideal for performing this experiment.

- Grouping of participants: Two groups are required.

- Implementation of a lesson plan: A plan has been prepared for a lesson, in which the concept of text-oriented vocabulary exercises is integrated with its steps.

- Test phase: The control tests should take place at specified time intervals. The participants in both groups should take the four control tests. But it is also important to mention that the selected retention interval was established according to Henrici (1995), who in his research spoke of three time intervals: thirty minutes, twenty-four hours and one week, respectively. Three control tests take place at these times and the fourth control test is taken three weeks after the learning phase. The fourth control test is for testing the retention performance after a longer period of time. So it should be tested to see if the words learned in this way after a period of three weeks could still be retrieved, which can be a proof of a good long-term retention performance. 
- Data analysis: For quantitative analysis, the collected data is analyzed using the SPSS program. As a qualitative analysis, the results are discussed, compared, and then conclusions are presented as well as implications for future research.

\subsection{Statistical Analysis}

The statistical software SPSS (Version 22) is used for the statistical analysis of the collected data. The score of the control tests in both groups are calculated in numbers (from 0 to 15). Each control test consists of 15 sentences and every correct answer has a point. In this study, the results of the tests are evaluated as such so that only the answer that corresponds to the expected answer is correct. The answers that deviate from the vocabulary in question, such as synonyms, words that are not complete, or even the translation or meaning of the words are not considered as correct answers and are not included in the rating. It should also be noted that orthographic and grammatical differences are not taken into account. After the evaluation, the results of the tests are submitted for analysis with the SPSS program. The collected data of both groups are compared using "independent-t test" and "two-way ANOVA test" and presented as average \pm SD (Note 18). The "Independent-t Test" will be used as an intergroup comparison with a variable. The "two-way ANOVA test" will be used for intergroup comparison with two variables. The results of these statistical tests are said to be statistically significant if the significance value (p-value) is less than the specified significance level. The specified level of significance for this study is 0.05 and 0.01 ; if the significance value is less than 0.05 , the result is called statistically significant. This is indicated in the figures with a star $\left(^{*}\right)$. If the significance value is less than 0.01 , the result is referred to as statistically significant, which is indicated in the figures with two stars $(* *)$. However, the result is said to be statistically insignificant if the significance value is greater than the significance level. This is indicated in the figures with (NS).

\subsection{Procedure}

The study was carried out once in June 2017 after the preparation of the test materials, agreement on the dates for the implementation of the learning phase and the grouping of the participants. Thirty-four GFL-Learners agreed to participate in the study and were divided into two groups each with 17 participants. The learning phase was carried out on 24.06.2017 for the control group from 12:00 to 15:30 and for the experimental group from 16:30 to 20:30 in the ÖKF with the prepared print materials, this phase took thirty minutes longer for the experimental group, because the participants in this group had to complete all three steps of the concept text-oriented vocabulary exercises and produce a text at the end. After the learning phase, the participants had a thirty-minute break, and then the first control test was given to both groups. The participants had thirty minutes time for this and also for the further control tests. After the first control test, the study and its rules were explained to the participants and they were informed about the further control tests. The participants needed to take the second control test after 24 hours, the third control test after 1 week and the last control test after 3 weeks. Since some participants could not appear for professional or personal reasons on the specified dates, it was agreed that the participants could take the tests by e-mail. However, it was also pointed out that the participants were not allowed to repeat or practice the learned words.

Unfortunately, only 10 learners in the control group participated in all phases as planned and received the control tests by e-mail, which in turn were filled and returned in time. The other participants sadly canceled their participation and therefore their data was completely deleted from the experiment.

Since the number of subjects in the first attempt did not reach the desired number, the experiment was carried out again in September 2017. This time, and in order to give the participants an instrumental motivation, it was decided - in agreement with the deputy of the Austrian Embassy in the ÖKF - that the students of the ÖKF who took part in this experiment received a reduction in the ÖKF enrollment (2,000,000 (two million rials)), but only on condition that they participated in all phases and completed the whole process in the determined times. This instrumental motivation motivated many GFL-learners in ÖKF, so 55 volunteers have volunteered for the second attempt, of which 43 participants participated in all phases.

Four dates were set for the second attempt and the participants were allowed to select one: There was a session on 31.08.2017 from 8:00 to 11:30; one on the same day from 12:00 to 16:00; a third session on 02.09.2017 from 08:00 to 11:30; and the fourth session on 02.09.2017 and from 12:00 to 16:00. The participants who selected the afternoon sessions formed the experimental group, and those who selected the morning sessions formed the control group. The learning phase was carried out with prepared printed materials and according to the plan designed. This phase took thirty minutes longer for the experimental group, because the participants in this group had to complete all three steps of the concept text-oriented vocabulary exercises and produce a text at the end. Then the participants got a thirty-minute break and after the break they did the first control test. After the first control test, the examination and its rules were explained to the participants and they were informed about the 
further control tests. As in the first experiment, all participants had to receive the control tests by e-mail, fill them and return them in a timely manner. It was also pointed out that the participants were not allowed to repeat or practice the learned words.

The learning phase on both days as well as all control tests were carried out as planned. At the end of this experiment, the number of participants reached the desired number and the study was successfully completed with 25 participants in the control group and 28 participants in the experimental group.

\section{Results}

The analysis of both collected data of the groups shows the following results, which are presented in tables and figures:

At first the experimental data were evaluated, then the results were compared with the independent samples t-test. Table 1 shows the results of this intergroup comparison.

Table 1. Independent samples t-test

\begin{tabular}{llllllll}
\hline & CG $(\mathrm{n}=25)$ & \multicolumn{3}{c}{ EC $(\mathrm{n}=28)$} & \multicolumn{3}{c}{$\mathrm{t}$-Test for Equality of Means } \\
Time & $\mathrm{M}$ & $\mathrm{SD}$ & $\mathrm{M}$ & $\mathrm{SD}$ & $\mathrm{t}$ & $\mathrm{df}$ & Sig. (2-tailed) \\
\hline $30 \mathrm{~min}$ & 7.56 & 4.02 & 10.07 & 3.16 & -2.54 & 51 & $.014^{* *}$ \\
$24 \mathrm{~h}$ & 7.64 & 3.91 & 10.28 & 3.15 & -2.72 & 51 & $.009^{* *}$ \\
1 week & 6.92 & 3.96 & 9.18 & 3.72 & -2.14 & 51 & $.037^{* *}$ \\
3 weeks & 7.48 & 3.98 & 9.79 & 3.49 & -2.25 & 51 & $.029^{* *}$ \\
\hline
\end{tabular}

Note. CG: Control group, EC: Experimental Group, n: Number of Test Persons, M: Mean; SD: Standard deviation.

In this table it is visible that in the first control test after thirty minutes of the learning phase in the EC $(\mathrm{n}=28)$ higher values $(M=10.07, S D=3.16)$ can be seen in comparison with the $C G(n=25, M=7.56, S D=4.02)$, which could be detected as a significant difference between the two groups in the first control test $(\mathrm{t}(51)=-2.54$, $\mathrm{p}=.014(* * \mathrm{p} \leq 0.01))$. From this difference one can conclude that the hypothesis I presented in this paper has been confirmed and that learners who have learned new words using the concept of text-oriented vocabulary exercises show a better short-term retention performance. They can better remember the textually learned words. Therefore, the text production has a positive influence on the short-term retention performance of the learners.

Interestingly, such a significant difference could also be calculated between both groups in the second control test after twenty-four hours of the learning phase. As the table shows, higher values $(\mathrm{M}=10.28, \mathrm{SD}=3.15)$ were found in the $E C(n=28)$ than in the $C G(n=25, M=7.64, S D=3.91)$. The independent samples t-test showed a significant difference between the groups ( $(51)=-2.72, \mathrm{p}=.009(* * \mathrm{p} \leq 0.01)$ ). This confirms the second hypothesis presented in this paper and can be interpreted as such that learners who have learned new words in a text-oriented manner can show better medium-term retention performance. Text production has a positive impact and can enable learners to remember textually learned words up to one day after the learning phase.

Regarding the long-term retention of the participants after one week, quite higher values $(\mathrm{M}=9.18, \mathrm{SD}=3.72)$ were observed in the EC $(n=28)$ than in the $C G(n=25, M=6.92, S D=3.96)$, but this difference could not be detected as significant $(\mathrm{t}(51)=-2.14, \mathrm{p}=.037, \mathrm{NS})$. This also applies to the long-term retention of the participants after three weeks, which was examined with the fourth control test. Here in the EC $(\mathrm{n}=28)$ also quite higher values were found $(\mathrm{M}=9.79, \mathrm{SD}=3.49)$ than in the $\mathrm{CG}(\mathrm{n}=25, \mathrm{M}=7.48, \mathrm{SD}=3.98)$, but this difference is not statistically significant $(\mathrm{t}(51)=-2.25, \mathrm{p}=.029$, NS). In light of these findings, the third and fourth hypotheses presented in this paper were refuted. One can therefore come to the conclusion that the learners who have learned new words using this concept, cannot show a particularly better long-term retention performance compared to their counter group. The text production thus has no particularly positive influence on the long-term retaining performance of the learners and cannot lead to the learners remembering the textually learned words in one week or three weeks. The following figure illustrates graphically the intergroup comparison. 


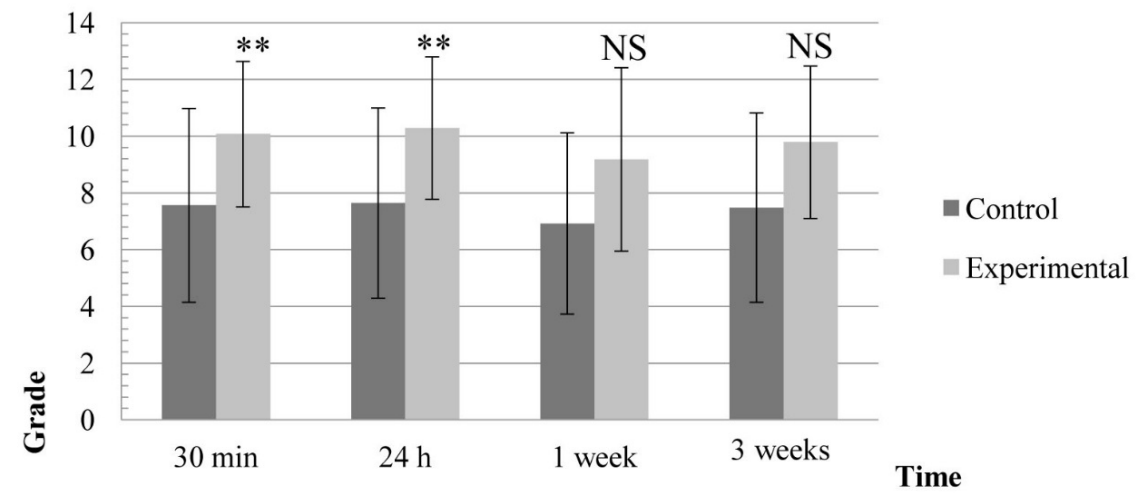

Figure 1. Independent samples t-test

In order to review the fifth hypothesis presented in this paper, the data collected from the subjects were sorted by gender and analyzed by using two-factorial analysis of variance (Two-Way-ANOVA). This test is useful if you want to examine the influence of two independent variables on one dependent variable. The dependent variable in this study is the retention performance, and one would like to examine whether this variable depends on the teaching method, i.e. the concept of text-oriented vocabulary exercises, and the gender of the learners or not. With a 2 (with / without text production) times 2 (gender) factorial analysis of variance, the number of remembered words was evaluated. The following table presents the results of this analysis in the women's group.

Table 2. Two-Way-ANOVA-Evaluation of the asked vocabulary in the women's group

\begin{tabular}{lllllll}
\hline \multirow{2}{*}{ Time } & $\begin{array}{l}\text { CG }(\mathrm{n}=14) \\
\text { Type III Sum of } \\
\text { Squares }\end{array}$ & df $($ Error $)$ & Mean Square & F & Sig. & $\begin{array}{l}\text { Partial } \\
\text { Squared }\left(\eta^{2}\right)\end{array}$ \\
\hline $30 \mathrm{~min}$ & $63.000^{\mathrm{a}}$ & 1,26 & 63.000 & 5.415 & .028 & .172 \\
$24 \mathrm{~h}$ & $96.571^{\mathrm{b}}$ & 1,26 & 96.571 & 8.374 & $.008^{* *}$ & .244 \\
1 week & $60.036^{\mathrm{c}}$ & 1,26 & 60.036 & 5.324 & .029 & .170 \\
3 weeks & $43.750^{\mathrm{d}}$ & 1,26 & 43.750 & 4.755 & .038 & .155 \\
\hline
\end{tabular}

Note. CG: Control group, EC: Experimental Group, n: Number of Test Persons.

This table shows that the gender has no significant influence on the short-term retention of female participants $(F$ $(1,26)=5.41, p=.028)$. Interestingly, a significant influence could be observed on the medium-term retention performance of female participants $\left(F(1,26)=8.37, p=.008(p \leq 0.01), \eta^{2}=.24\right)$. This is the only significant difference in the women's group. Gender had no significant effect on the long-term retention of female participants after one week $(F(1,26)=5.32, p=.029)$ and neither did it have after three weeks $(F(1,26)=4.76$, $p=.038)$. This can be interpreted in such a way that the text production can enable women to remember the new learned words better after one day compared to their control group. Text production has thus a positive effect on the medium-term retention of women. The following figure shows this analysis in the women's group:

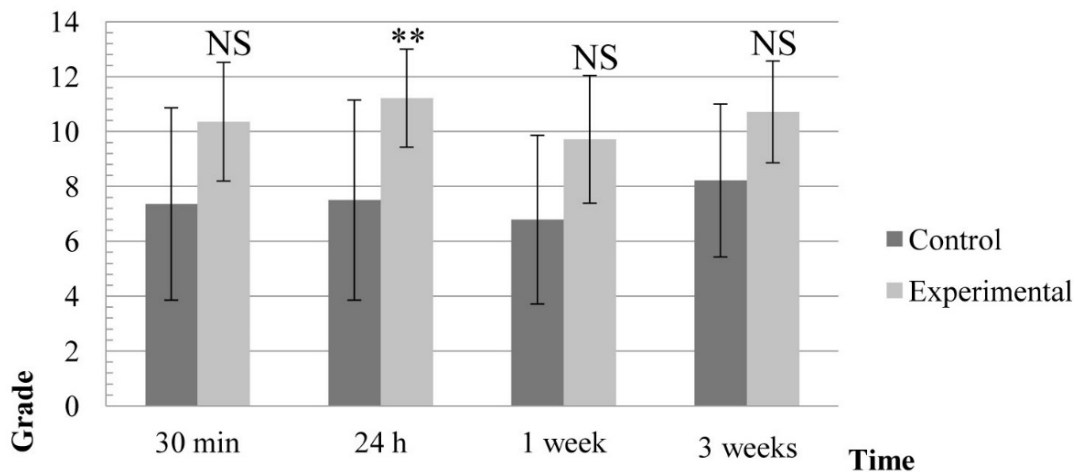

Figure 2. Two-way-ANOVA—Evaluation of the required vocabulary in the women's group 
As can be seen in Figure 2, gender has a positive influence on the medium-term retention performance of women. To find out if gender has such an influence on men as well, the number of remembered words was evaluated by male participants using 2 (with / without text production) times 2 (gender) factorial analysis of variance. The following table presents the results of this analysis in the male group.

Table 3. Two-Way-ANOVA-Evaluation of the asked vocabulary in the men group

\begin{tabular}{lllllll}
\hline \multirow{2}{*}{ Time } & $\begin{array}{l}\text { CG }(\mathrm{n}=11) \\
\text { Type III Sum of } \\
\text { Squares }\end{array}$ & df (Error) & Mean Square & F & Sig. & Partial Eta Squared $\left(\eta^{2}\right)$ \\
\hline $30 \mathrm{~min}$ & $23.846^{\mathrm{a}}$ & 1,23 & 23.846 & 1.558 & .224 & .063 \\
$24 \mathrm{~h}$ & $14.589^{\mathrm{b}}$ & 1,23 & 14.589 & 1.079 & .310 & .045 \\
1 week & $14.837^{\mathrm{c}}$ & 1,23 & 14.837 & .761 & .392 & .032 \\
3 weeks & $32.918^{\mathrm{d}}$ & 1,23 & 32.918 & 1.767 & .197 & .071 \\
\hline
\end{tabular}

Note. CG: Control group, EC: Experimental Group, n: Number of Test Persons.

According to this table, gender did not significantly affect the retention performance of male participants. The $\mathrm{F}$-value for short-term retention is not statistically significant $(\mathrm{F}(1,23)=1.56, \mathrm{p}=.224)$. This also applies to the $\mathrm{F}$-value for medium-term retention $(\mathrm{F}(1,23)=1.08, \mathrm{p}=.310)$ and also for the long-term retention after one week $(\mathrm{F}(1,23)=.76, \mathrm{p}=.392)$ and after three weeks $(\mathrm{F}(1,23)=1.77, \mathrm{p}=.197)$. This means that gender is not a factor that significantly affects the retention of men. The following figure illustrates this analysis in the male group:

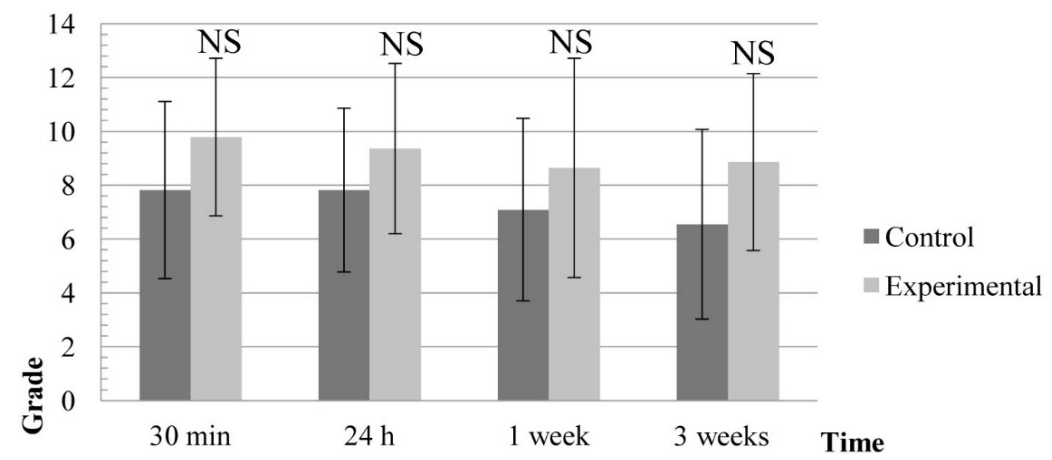

Figure 3. Two-way-ANOVA-Test-Evaluation of the required vocabulary in a group of men

The fifth hypothesis has been partially confirmed. Gender had a significant influence on female participants only on the medium-term retention performance.

Another independent variable that can influence the retention of participants is the age of the learners. In order to investigate, whether there is a correlation between the positive influence of text production in the concept of text-oriented vocabulary exercises and the short-term, medium-term and long-term retention and age of the learners or not, the experimentally collected data were sorted into four groups according to the age of the subjects: Some subjects were under the age of 20, some between 20 and 30, some between 30 and 40 and some over 40 years old. Since the number of participants in the groups "under 20 years" and "over 40 years" was less than 5, this analysis was performed only in the groups "between 20 and 30 years" and "between 30 and 40 years". The number of remembered words in these two age groups was evaluated with a 2 (with / without text production) times 2 (age group) factorial analysis of variance. The following table presents the results of this analysis "between 20 and 30 years' age group".

Table 4. Two-Way-ANOVA-Evaluation of the required vocabulary in the age group between 20 and 30 years

\begin{tabular}{lllllll}
\hline \multirow{2}{*}{ Time } & CG $(\mathrm{n}=15)$ & \multicolumn{3}{c}{ EC $(\mathrm{n}=21)$} & & \\
& Type III Sum of Squares & df $($ Error $)$ & Mean Square & $\mathrm{F}$ & Sig. & Partial Eta Squared $\left(\eta^{2}\right)$ \\
\hline $30 \mathrm{~min}$ & $10.496^{\mathrm{a}}$ & 1,34 & 10.496 & .796 & .379 & .023 \\
$24 \mathrm{~h}$ & $17.150^{\mathrm{b}}$ & 1,34 & 17.150 & 1.438 & .239 & .041 \\
1 week & $12.007^{\mathrm{c}}$ & 1,34 & 12.007 & .819 & .372 & .024 \\
3 weeks & $22.667^{\mathrm{d}}$ & 1,34 & 22.667 & 1.451 & .237 & .041 \\
\hline
\end{tabular}

Note. CG: Control group, EC: Experimental Group, n: Number of Test Persons. 
As can be seen from this table, age did not significantly affect subjects' retention performance. The F-value for short-term retention is statistically insignificant $(\mathrm{F}(1,34)=.80, \mathrm{p}=.379)$. This also applies to the medium-term retention $(\mathrm{F}(1,34)=1.44, \mathrm{p}=.239)$ and to the long-term retention after one week $(\mathrm{F}(1,34)=.82, \mathrm{p}=.372)$ and after three weeks $(\mathrm{F}(1,34)=1.45, \mathrm{p}=.237)$. One can therefore conclude that the participants in the age group between 20 and 30 years can remember the learned word, whether they have learned the words text-oriented or not, and age has no significant impact on this performance. The following figure illustrates this analysis in this age group:

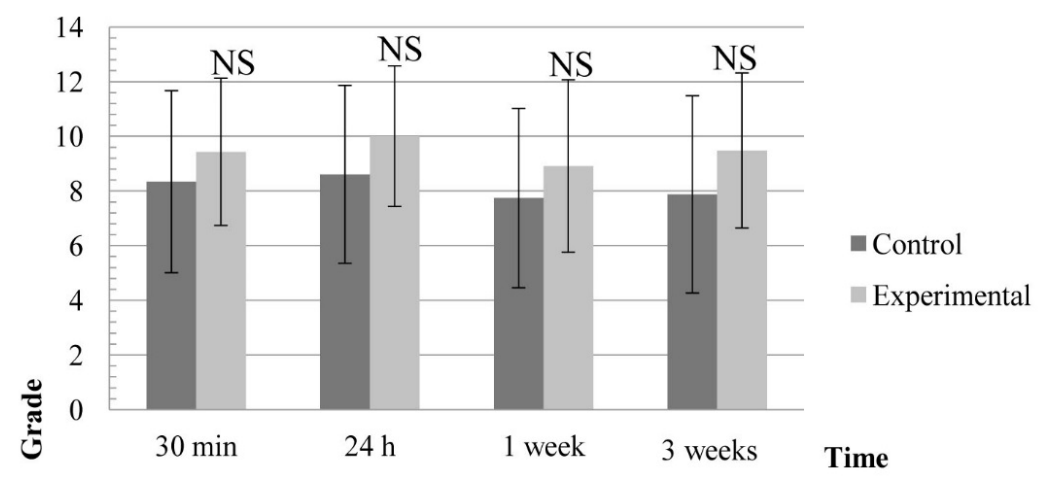

Figure 4. Two-Way-ANOVA-Test—Evaluation of the required vocabulary in the age group between 20 and 30 years

As this figure shows, no significant effect of age could be calculated for retention performance. In order to find out if age affects the retention performance of 30 to 40 year old learners, the 2 (with / without text production) times 2 (age group) factorial analysis of variance was also performed for this group of participants. The following table presents the results of this analysis in the age group between 30 and 40 years.

Table 5. Two-Way-ANOVA-Evaluation of the required vocabulary in the age group between 30 and 40 years

\begin{tabular}{lllllll}
\hline \multicolumn{2}{l}{ CG $(\mathrm{n}=8)$} & \multicolumn{2}{c}{ EC $(\mathrm{n}=5)$} & & \\
Time & Type III Sum of Squares & df (Error) & Mean Square & F & Sig. & Partial Eta Squared $\left(\eta^{2}\right)$ \\
\hline $30 \mathrm{~min}$ & $88.167^{\mathrm{a}}$ & 1,10 & 88.167 & 8.686 & $.015^{* *}$ & .465 \\
$24 \mathrm{~h}$ & $80.667^{\mathrm{b}}$ & 1,10 & 80.667 & 6.020 & $.034^{*}$ & .376 \\
1 week & $66.667^{\mathrm{c}}$ & 1,10 & 66.667 & 4.975 & $.050^{*}$ & .332 \\
3 weeks & $45.375^{\mathrm{d}}$ & 1,10 & 45.375 & 5.105 & $.047^{*}$ & .338 \\
\hline
\end{tabular}

Note. CG: Control group, EC: Experimental Group, n: Number of Test Persons.

The results of this analysis are interesting. As can also be seen from the above table, the calculation of the two-factorial analysis of variance demonstrates a significant influence on the retention performance of the 30 to 40 year old subjects in all four time intervals. A significant influence is noticeable on the short-term retention performance $(\mathrm{F}(1,10)=8.69, \mathrm{p}=.015(\mathrm{p} \leq 0.01), \eta 2=.46)$, as well as on the medium-term retention performance $(\mathrm{F}(1,10)=6.02, \mathrm{p}=.034(\mathrm{p} \leq 0.05), \eta 2=.38)$ and long-term retention after one week $(\mathrm{F}(1,10)=$ $4.98, p=.050(p \leq 0.05), \eta 2=.33)$ and after three weeks $(F(1,10)=5.10, p=.047(p \leq 0.05), \eta 2=.34)$. These effects also turned out to be quite strong, especially in terms of short-term retention: $46 \%$, as indicated by the $\eta 2$ values. This can be interpreted as such that text production can have a positive influence on the retention performance of learners aged 30 to 40 and enables them to better remember the textually learned words - compared to their peers - in short-, medium- and long-term. This result leads to the confirmation of the sixth hypothesis presented in this paper. It should be noted, however, that the number of 30 to 40 year old subjects in the experimental group was low, which may affect the results presented in this age group. The following figure illustrates this analysis in this age group: 


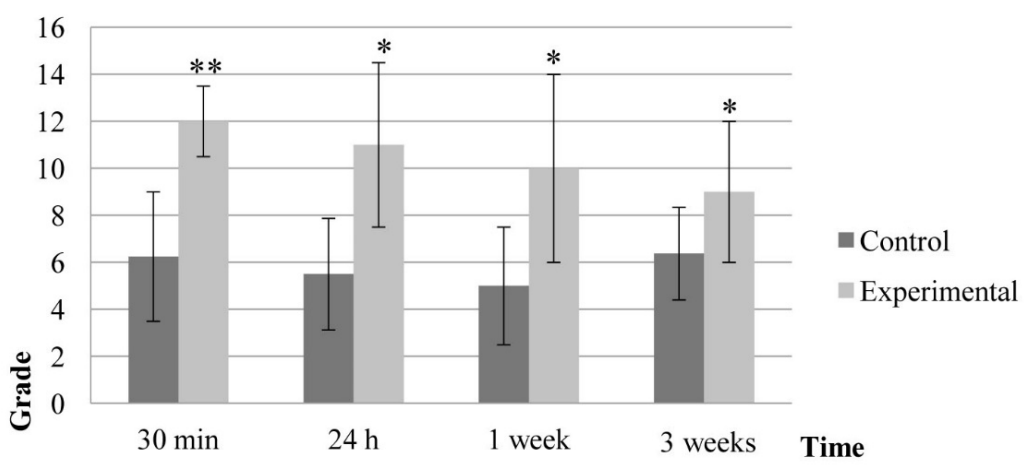

Figure 5. Two-Way-ANOVA—Evaluation of the required vocabulary in the age group between 30 and 40 years

At the sight of the analyses presented in relation to the age of the learners, the sixth hypothesis was confirmed. Age had a significant influence on the short-term, medium-term and long-term retention of the 30 to 40 -year-old participants, which means that there is a correlation between the age of learners and the positive impact of text production in the concept of text-oriented vocabulary exercises on short-term, medium-term and long-term retention of learners.

\section{Discussion and Implication for Future Research}

According to the obtained results of this study, with regard to the research questions and based on the statistical data analysis, it could be stated that the text production has a positive influence on the learners' short-term and medium-term retention performance. The Levels of Processing Effect can be a good explanation for this result. However, text production was not a good intervention to improve long-term retention after one week and three weeks and had no significant impact on it. This can be attributed to the duration of the intervention. A relatively short-term intervention measure cannot lead to relatively long-term intervention. This may be an implication for future research. Whether the long-term retention of the learners can be improved by more intensive confrontation with the text production tasks or not can be investigated.

The results of the study also shows that there is a correlation between the positive impact of text production in the concept of text-oriented vocabulary exercises on medium-term retention and gender of learners, and that an advantage for the female gender could be found. This was to be expected according to the previously mentioned explanations in this context. There are also implications for future research. Whether a more intensive confrontation with text production tasks can positively influence the retention performance of men or not can be subject to examination.

It could also be determined, that there is a correlation between the positive impact of text production in the concept of text-oriented vocabulary exercises on the short-term, medium-term and long-term retention and age of the learners. Mature adults (the 30 to 40 -year-old learners) have shown a better retention performance in all four specified time intervals. As adults learn a new language, especially analytically and by means of rules and their needs, text production could be a good intervention measure for learners in this age group. How can one achieve the same positive impact of text production in the other age groups? Do other factors play a role here? Is it possible to improve the retention performance in the other age groups through more intensive confrontation with text production tasks? These are questions in this area that can lead the way to further research.

\section{Acknowledgments}

This work was supported by Research institute ReCeLLT. The authors would like to express their heartfelt gratitude to Parvaneh Sohrabi for her academic support and dedication, to Fereshteh Bahmannezhad, Amir Alaienia, Elnaz Gh. Shahneshin and Shahin Jamali for their kind supports.

\section{References}

Aguado Padilla, K. (2002). Imitation als Erwerbsstrategie: Interaktive und kognitive Dimensionen des Fremdsprachenerwerbs. Bielefeld: Universität Bielefeld.

Aitchison, J. (1997). Wörter im Kopf. Eine Einführung in das mentale Lexikon. Tübingen: Niemeyer. https://doi.org/10.1515/9783110938470

Bočkova, V. (2002). Vzdělávání-Prưvodní jev života. Olomouc: Univerzita. 
Craik, F., \& Lockhart, R. (1972). Levels of processing: A framework for memory research. Journal of Verbal Learning \& Verbal Behavior, 11(6), 671-684. https://doi.org/10.1016/S0022-5371(72)80001-X

Elbers, L. (1997). Output as input: a constructivist hypothesis in language acquisition. Archives de Psychologie, (65), 131-140.

Halpern, D. F. (2000). Sex differences in cognitive abilities (3rd ed.). Lawrence Erlbaum Assciates: Mahwah.

Henrici, G. (1995). Spracherwerb durch Interaktion? Eine Einführung in die fremdsprachenerwerbsspezifische Diskursanalyse. Baltmannsweiler: Schneider Verlag Hohengeren.

Hochstadt, C., Krafft, A., \& Olsen, R. (2013). Deutschdidaktik: Konzeption für die Praxis. (Deutschdidaktik) Stuttgart: UTB GmbH.

Honnef-Becker, I. (2000). Wortschatzarbeit in der Schreibwerkstatt: Plädoyer für eine textbezogene Wortschatzdidaktik. In P. Kühn (Ed.), Wortschatzarbeit in der Diskussion (pp. 149-177). Hildesheim: Olms.

Kersten, S. (2010). Das mentale Lexikon und Vokabellernen in der Grundschule. In S. Sahel \& R. Vogel (Eds.), NLK-Proceedings: 10. Norddeutsches Linguistisches Kolloquium (pp. 66-88). Bielefeld: Universität Bielefeld. https://doi.org/10.2390/biecoll-nlk2009-3

Klippel, F. (1995). Wörternetze. In K. R. Bausch, H. Christ, F. G. Königs, \& H. J. Krumm (Eds.), Erwerb und Vermittlung von Wortschatz im Fremdsprachenunterricht. Arbeitspapiere der 15. Frühjahrskonferenz zur Erforschung des Fremdsprachenunterrichts (pp. 101-107). Tübingen: Narr.

Köster, L. (1994). Semantisierungsprozesse im Unterricht Deutsch als Fremdsprache: Eine Analyse von Bedeutungserklärungen im Unterricht mit fortgeschnittenen Lernen. Frankfurt am Main: Peter Lang.

Kühn, P. (2000). Kaleidoskop der Wortschatzdidaktik und -methodik. In P. Kühn (Ed.), Wortschatzarbeit in der Diskussion (pp. 5-28). Hildesheim: Olms.

Kühn, P. (2006). Interkulturelle Semantik. Nordhausen: Bautz.

Kühn, P. (2007). Rezeptive und produktive Wortschatzkompetenzen. In H. Willenberg (Ed.), Kompetenzhandbuch für den Deutschunterricht. Auf der empirischen Basis des DESI-Projekts (pp. 160-167). Baltmannsweiler: Schneider.

Lautenbacher, S., Güntürkün, O., \& Hausmann, M. (2007). Gehirn und Geschlecht: Neurowissenschaft des kleinen Unterschieds zwischen Frau und Mann. (Springer e-books.) Berlin, Heidelberg: Springer Medizin Verlag Heidelberg. https://doi.org/10.1007/978-3-540-71628-0

Löschmann, M. (1993). Effiziente Wortschatzarbeit. Alte und neue Wege. Frankfurt am Main: Peter Lang.

Ludinová. (2008). Lerntypengerechte Wortschatzarbeit im Deutschunterricht für Erwachsene. Retrieved from https://is.muni.cz/th/79926/pedf_m/DIPLOMARBEIT.pdf

Müller, B. D. (1994). Wortschatzarbeit und Bedeutungssvermittlung. Berlin: Langenscheidt.

Neveling, C. (2004). Wörterlernen mit Wörternetzen: Eine Untersuchung zu Wörternetzen als Lernstrategie und als Forschungsverfahren. Tübingen: Narr.

Niggemann, W. (1977). Praxis der Erwachsenenbildung. Freiburg im Breisgau: Herder.

Pilzecker, B. (1996). Kognition und Wortschatzarbeit. Zielsprache Deutsch, 27(3), 130-134.

Pispers, R., \& Dabrowski, J. (2011). Neuromarketing im Internet. München: Haufe Verlag.

Quetz, J. (1998). Der systematische Aufbau eines mentalen Lexikons. In J. P. Timm (Ed.), Englisch lernen und lehren. Didaktik des Englischunterrichts (pp. 272-290). Berlin: Cornelsen.

Robra, K. (2000). Eigensemantisierung. Wie Lernende die Bedeutungen unbekannter Lexik in der Lehrbuchphase möglichst selbstständig herausfinden können. Französisch heute, 31, 37-46.

Scherfer, P. (2007). Wortschatzübungen. In K. R. Bausch, H. Christ, \& H. J. Krumm (Eds.), Handbuch Fremdsprachenunterricht. (5th ed., pp. 280-283). Tübingen, Basel: A. Francke.

Stangl, W. (2014). Speicherabhängige Gedächtnisformen. Retrieved from http://arbeitsblaetter.stangl-taller.at/GEDAECHTNIS/ModelleSpeicher.shtml 
Steinhof, T. (2011). Unterrichtsideen zur textorientierten Wortschatzarbeit. Aneignung- und Gebrauchskontexte lexikalischer Mittel. In I. Pohl \& W. Ulrich (Eds.), Wortschatzarbeit: Deutschunterricht in Theorie und Praxis (DTP) (pp. 577-591). Hohengehren: Schneider Verlag.

Swain, M. (1985). Communicative Competence: some Roles of Comprehenssible Input and Comprehenssible Output in its Development. In S. Gass \& C. Madden (Eds.), Input in Second Language Acquisition (pp. 235-256). New York: Newbury House.

Wolff, D. (2000). Wortschatzarbeit im Fremdsprachenunterricht. Eine kognitivistisch-konstruktivistische Perspektive. In P. Kühn (Ed.), Wortschatzarbeit in der Diskussion (pp. 99-124). Hildesheim: Olms.

Žavski-Bahč, M. (2012). Überlegungen zum mentalen Lexikon im DaF-Unterricht oder wie Oktoberfest zum Festival im Oktober wird. Jezikoslovlje, 13(3), 785-807 https://hrcak.srce.hr/file/140137.

\section{Notes}

Note 1. German as foreign language

Note 2. The original title is "Germanistische Linguistik".

Note 3. The original title is "Studien zu Deutsch als Fremdsprache, Wortschatzarbeit in der Diskussion".

Note 4. The original title is "Kaleidoskop der Wortschatzdidaktik und -methodik, traditionelle Wortschatzvermittlung: Kritische Bestandsaufnahmen und Perspektiven".

Note 5. The original title is "Evaluation rezeptiver und produktiver Wortschatzkompetenzen, Plädoyer für textuelle und konstruktivistisch angelegte Wortschatzaufgaben".

Note 6. The original title is "Interkulturelle Semantik".

Note 7. The original title is "rezeptive und produktive Wortschatzkompetenz".

Note 8. The original title is "Wörter im Kopf, eine Einführung in das mentale Lexikon".

Note 9. The original title is "Wörternetze".

Note 10. The original title is "der systematische Aufbau eines mentalen Lexikons".

Note 11. The original title is "Wörterlernen mit Wörternetzen, eine Untersuchung zu Wörternetzen als Lernstrategie und als Forschungsverfahren".

Note 12. The original title is "Das mentale Lexikon und Vokabellernen in der Grundschule".

Note 13. The original title is "Überlegungen zum mentalen Lexikon im DaF-Unterricht".

Note 14. The original title ist "Wortschatzarbeit in der Schreibwerkstatt: Plädoyer für eine textbezogene Wortschatzdidaktik".

Note 15. First language acquisition.

Note 16. Austrian Cultural Forum in Tehran (Österreichisches Kulturforum Teheran).

Note 17. Common European Framework of Reference for Languages.

Note 18. Standard deviation.

\section{Copyrights}

Copyright for this article is retained by the author(s), with first publication rights granted to the journal.

This is an open-access article distributed under the terms and conditions of the Creative Commons Attribution license (http://creativecommons.org/licenses/by/4.0/). 